\title{
Ritmik Yetenek ile Akademik Başarı Arasındaki İlişki ${ }^{1}$
}

DOI: $10.26466 /$ opus.626271

\author{
Hüseyin Y1ldız ${ }^{*}$ Oğuzhan Yoncalık ${ }^{* *}$ \\ * Bilim Uzmanı, Kırıkkale Üniversitesi, Sağlık Bilimleri Enst., Kırıkkale/Türkiye \\ E-Posta: yldzhsynyldz@gmail.com \\ ORCID: 0000-0002-7996-5192 \\ ** Prof. Dr, Kırıkkale Üniversitesi, Spor Bilimleri Fakültesi, Kırıkkale / Türkiye \\ E-Posta: oguzhanyoncalik@kku.edu.tr \\ ORCID: 0000-0003-2289-1257
}

\section{Öz}

Bu araştırma, 2018-2019 Ĕ̆itim Öğretim yılında Kırıkkale il merkezinde bulunan dört farklı lisede eğitimlerine devam eden 90 (48 kız- 42 erkek) 9. sinıf öğrencisi üzerinde gerçekleştirilmiştir. Öğrencilerin akademik başarılarının belirlenmesinde Matematik, Türk Dili ve Edebiyatı derslerinin notları ve genel not ortalamaları dikkate alınmıştır. Öğrencilerin ritmik yetenekleri Wekiart (1989) ritim beceri gözlem formu (Rhytmic Compentence Analysis Test-RCAT) ile test edilmiştir. Ritmik yetkinlik analizi testi, bireyin ritim yetkinliğini, altta yatan müzik ritmine göre bir hareket görevi gerçekleştirme yeteneğini test ederek değerlendirmek üzere tasarlanmıştır. Öğrencilerin test uygulamaları kamera ile kayıt altına alınmıştır. Hoparlör öğrencilerin metronomu rahatlıkla duyabilecekleri mesafeye konulmuştur. Kaydedilen video görüntülerinin değerlendirilmesinde alan uzmanlarına başvurulmuştur. Halk Oyunları alanında en az 10 yıl tecrübeli ve bu alanda ikinci kademe antrenörlük belgesine sahip iki hakem ile değerlendirmeler yapılmıştır. Hakemlerin birbirlerinden etkilememeleri için farklı günlerde video kayıtlar izletilerek değerlendirme formları doldurtulmuştur. Veri analizinde SPSS 18 paket programı kullanılmıştır. Sonuç olarak katılımcıların ritmik yetenek puanları ile akademik başarı not ortalamaları arasında istatiksel olarak anlamlı bir ilişki tespit edilememiştir.

Anahtar Kelimeler: Ritim, Ritmik yetenek, Akademik başarı

\footnotetext{
${ }^{1}$ Bu makale Kırıkkale Üniversitesi Sağlık Bilimleri Enstitüsü Beden Eğitimi ve Spor Ana Bilim Dalında tamamlanmış Yüksek Lisans tezinden üretilmiştir.
} 


\title{
The Relationship Between Rhythmic Ability and Academic Success
}

\begin{abstract}
This research studied in Kirlkkale province in 2018-2019 academic year. This study involving 90 students which they are in 9th grade in their education in four different high schools in (48 females - 42 males). In determining students' academic achievement, Mathematics, Turkish Language and Literature course notes and general notes averages are taken into consideration. Rhythmic abilities of students. In the study we applied Wekiart (1989) rhythm skill observation form (Rhytmic) Compentence Analysis Test (RCAT). Rhythmic competence analysis test, the rhythm competence of the individual, the underlying music test which was designed to evaluate a persons ability to perform a movement task according to the rhythm. Students test applications are recorded with the camera. We put the speaker distance in order to students can easily hear the metronome. We have discussed with experts from related field researchers and two referees which have got at least 10 years of experience and second degree coach certificate in the folklore for evaluating the recorded video images To prevent one referee's effect to each other video recordings has been watched diffrent times by them. Evaluation forms completed diffrent times. In the data analysis spss 18 package program has been used. As a result, there is no statistically significant relationship was found rhythmic between ability scores and academic achievement grade point averages.
\end{abstract}

Keywords: Rhythm, Rhythmic Ability, Academic Achievement 


\section{Giriş}

Öğrencilerin yeteneklerinin tam anlamıyla ortaya çıkarılması ve bunlara uygun stratejilerin geliştirilmesi dikkate değerdir. Zekanın baskın ve tek bir yetenek şeklinde değil, farklı ve özel boyutlara sahip olduğunu ifade eden çoklu zeka kuramına göre kişiler, yalnızca sözel ve sayısal yeteneklerle değil aynı zamanda bedensel, sosyal ve müziğe ilişkin yeteneklere de sahip olabilmektedir. Çalışmanın konusu kapsamında Müziksel zeka, "müzik formlarının farkında olarak onların ayırt edilmesi ve ifadesi" şeklinde ifade edilmektedir (Eyyam, Meneviş ve Doğruer, 2010). Bu çalışma ile öğrencilerin ritmik yetenekleriyle akademik başarıları arasındaki ilişkinin anlatılması hedeflenmektedir.

\section{Ritmik Beceri}

Yunanca'da "Rho" (akmak) kelimesinden ortaya çıkmış olan ritim kelimesi, pek çok faaliyetin ifade edilmesi için kullanılmaktadır. Yaşamın pek çok alanında varlık gösteren ritim en çok müzikte ve düzenli şekilde yapılan bedensel hareketlerde ortaya çıkmaktadır. Diğer bir deyişle ritim bir bakıma düzen anlamına da gelmektedir (Gerek ve Kitkat, 2006). Diğer yandan ritim kelimesi Türkçe 'de ahenk, musiki, müzikalite ve armoni, Osmanlıca' da insicam, tecânüs, teellüf, selâset kelimeleri ve İngilizce' de de rhythm, harmony kelimeleriyle eş değer anlamlara sahiptir (Wales, 1989). Ama bütün bu kelimelerin hepsinin de kökleri belli bir akış düzeni, düzenli şekilde tekrar edilen bedensel hareket, simetri anlamlarına gelen rhythmos sözcügüune dayanmaktadır (Liddell ve Scott, 1996).

Performans ritmi zaman ve mekana bağlı olacak şekilde ortaya çıkmış olan motor becerilerindeki başarılı olma kabiliyeti şeklinde tanımlanmaktadır (Pollatou, Konstantina ve Vasilios, 2005). Bu nedenle, istek duyularak ve belli bir düzen dahilinde gerçekleştirilen her eylemin ölçü ve değerleri "hız ile ritim" arasındaki ilişki bağlamında değerlendirilmektedir (Langhans ve Lau, 1972). Ayrica her eylem belli bir ritim kapsamında gerçekleşmekte olup ritim olmaksızın ortaya konan hareketler noktalama işaretleri olmayan ve anlamlandırılamayan cümlelere benzemektedir (Tortora, 2010). 
Ritim ölçülebilir olması gerekmektedir. Ölçme denildiğinde, biliş, duyuş ve deviniş sınaması için, davranışların çeşidine, içeriğine bağlı olarak farklılık gösteren yöntem ve araçlar akla gelmektedir (Uçan, 1997). Bununla birlikte ritmin ölçülüp değerlendirilmesiyse, ölçme işlemini gerçekleştiren bireylere bağlı olarak farklılık gösteren bir kısımdır. Performansın değerlendirilmesi ise, kişilerin kişilik özellikleri, gelişimi ve davranışlarının belirli bir sistem içerisinde değerlendirilmesini gerektirmektedir (Kaynak, 2019).

Genel olarak spor ile ilgili bütün eğitimlerde yaratıcılık çok önemlidir. Bu nedenle sporla uğraşanların yaratıcılıklarını ve tekniklerini ilerleterek, fiziksel yeterlilik edinmelerine yönelik çalışmalar artırılmalıdır. Yapılan bütün bu çalışmaların temelinde ritim bulunmaktadır (Doğan ve Altay, 1990).

Hareketlerde var olan zamansal boyut ritim becerisi ile ortaya konmaktadır. Ayrıca ritim becerisi motor hafızada halihazırda var olan bir ritmin tekrar ortaya çıkarılmasına imkan sağlamaktadır (Minz, 2003). Pek çok spor etkinliğinde ritim uygulanmaktadır. Örneğin; basketbol oynanırken "potaya doğru gidiş, top sürme, turnike ve dripling" gibi hareketlerin hepsi dinamiklik içerdiğinden ritmi de içinde barındırmaktadır (Sayın, 2011). Hatta oryantiring sporundan hareketlerin ritmik olarak yapilmasi sonuca bile etki etmektedir (Langhans ve Lau,1972). Bu sporda açık alanda koşan sporcular bir anda "sekme, yana kayma ya da sıçrayarak atlama" benzeri birtakım hareketlere geçmek zorunda kalmaktadır. Futbolcular ile ilgili yapılan bir diğer çalışmada, maç esnasında oyuncuların yer değiştirmesi, top ile yer değiştirmesi, yan ve geriye doğru yapılan hareketlerin hepsinin başarılı bir şekilde gerçekleştirilebilmesi için ritim maharetinin gelişmiş olması gerektiğine vurgu yapılmıştır (Moreno, 2001).

\section{Akademik Başarı}

Okulda okutulan derslerde geliştirilen ve eğitimcilerce takdir edilen notlarla, test puanlarıyla veya her ikisi ile belirlenen beceriler veya kazanilan bilgilerin ifadesidir (Erdoğdu, 2006). Arıcı'ya (2007) göre ise öğrencinin psikomotor ve duyuşsal gelişiminin dışında kalan, bütün program alanlarındaki davranış değişmelerini ifade eder. “Öğrencinin birtakım bilgi ve beceri kazanmayı gerektiren konularda istenilen düzeyde yeterlilik 
göstermesi ya da kendisine ölçme araçları uygulanan öğrencinin olumlu tepkileriyle ortaya çıkan sonuç" tur.

Dane, Kudu ve Balkı'ya (2009) göre ise, akademik başarıyı etkileyen faktörler arasında: öğrencinin kendisi, okul ve sınıf ortamı, aile, öğretmen, sınıf arkadaşları, öğretim yöntemleri gibi faktörler bulunmaktadır. Öğrencilerin başarılı olmalarını etkileyen faktörlerden biri bizzat öğrencilerin iyi çalışma tutum ve alışkanlıklarına sahip olmaları veya olmamalarıdır (Peker ve Mirasyedioğlu, 2003; Sarı ve Ekici, 2018; Sarı, Yıldızlı ve Arıkan, 2017).

\section{Araştırmanın Amacı}

$\mathrm{Bu}$ çalışma da amaç, ritmik yetenek ile akademik başarı arasındaki ilişkinin araştırılması ve değerlendirilmesidir.

\section{Materyal ve Metot}

Araştırmanın Modeli ve Grubu: Bu araştırma betimsel bir çalışmadır. Araştırmanın grubu, 2018-2019 Eğitim Öğretim yılında Kırıkkale il merkezinde bulunan dört farklı lisede eğitimlerine devam eden 90 (48 kız42 erkek) 9. sınıf öğrencisi üzerinde gerçekleştirildi. Katılımcıların yaş aralığ 14-15 olarak belirlenmiştir. Katılımcılarda herhangi bir fiziksel rahatsızlık ve engel gözlemlenmemiştir.

\section{Verilerin Analizi ve İşlem;}

Ritmik Yetkinlik Analizi Testi: Araştırmada Rhytmic Compentence Analysis Test (RCAT) kullanılmıştır (Weikart, 1989). Ritmik yetkinlik analizi testi, bireyin ritim yetkinliğini, altta yatan müzik ritmine göre bir hareket görevi gerçekleştirme yeteneğini test ederek değerlendirmek üzere tasarlanmıştır. Test oturarak el ve ayak vurma hareketleri ve ayakta yerinde sayma ve yürüme hareketleri olmak üzere iki seviyede uygulanır. Testte her seviye için aynı müzik seçimi kullanılmalıdır. Çalışma anında diğer öğrencilerin birbirinden ayrı olması gerekmektedir. Bir kayıt cihazı ve iki ayrı metronom hızı kullanılmalıdır. Çalışmada bir müzikal seçim, yak- 
laşık 120 metronom ritmine sahip olmalı ve diğer seçim, yaklaşık 132 metronom ritmine sahip olmalıdır. Teste başlamak için yapılacak hareketler hem öğrenci hem de uygulayıcı tarafından anlaşılmış olmalıdır. Uygulayıcı her bir öğrenciyi arkadaşça bir sohbetle bilgilendirmeli ve rahatlatmalıdır. Öğrencilerin istenen hareketleri anladığından emin olunmalıdır. Müzik ile yapılacak hareketleri gösteren kısa bir gösterip yaptırma oyunu oynanabilir. Weikart testle ilgili genel bir uyarı yapmıştır. Bu uyarıya göre test uygulanırken kesinlikle öğrenciye görsel veya işitsel yardım sağlanmamalıdır (Weikart,1989;377).

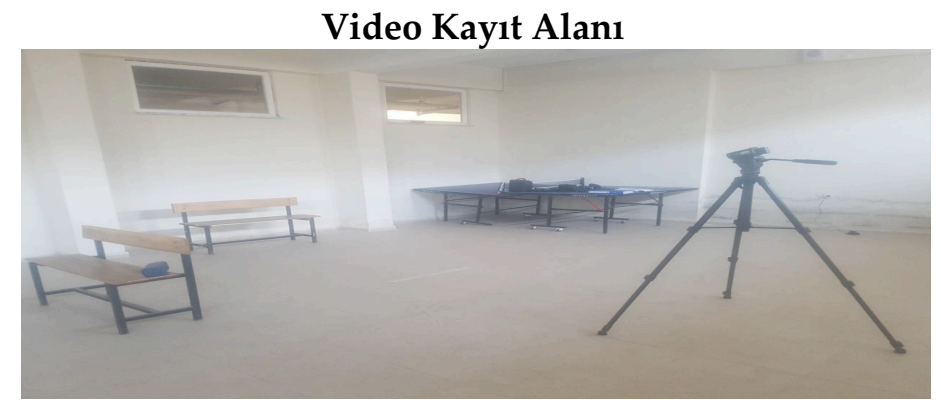

Şekil 1. Testin uygulandı̆̆ı alan

Öğrencilerin uygulamaya başladığı yer ile kamera arasındaki uzaklık 3.15 metre olacak şekikde ayarlanmıştır. Metronom cihazı ve hoparlör ögrrencilerin metronomu rahatlıkla duyabilecekleri mesafeye ve öğrencilerin sağ tarafında bulunan sıranın üzerine konulmuştur.

\section{Testin Uygulanması}

Hareketler 120 ve 132 metronom hızı olmak üzere iki farklı tempo da uygulanmıştır. Öğrencilere, çalışma başlamadan önce test hakkında bilgi verilmiştir. Yapacakları hareketlerin standart seviyesi gösterilmiştir. Her öğrenci uygulama sırasında diğer öğrencilerden bağımsız bir şekilde hareketleri yapmıştır. Çalışma yapılırken, hiçbir öğrenciye görsel veya işitsel yardım yapılmamıştır. Çalışmaya katılan öğrenciler, her hareketi 6 defa tekrar etmiştir. Bir öğrenci çalışma boyunca iki farklı metronomda toplamda 72 hareket yapmıştır. 120 ve 132 metronom hızında yapılan hareketler aynıdır. Bu hareketler sırasıyla (Söğut 2009); 
İki El Dizlere Vurma: Öğrenciler harekete başlamadan önce, iki el dizlerin üstünde sabit bir şekilde durmaktadır. Metronomdan gelen ritim sesiyle birlikte önce yukarı daha sonra da aşağıya doğru ellerini hareket ettirir. Toplamda öğrenciler bir hareket boyunca 6 ritim vuruşu yapmaktadır.

Íki El Strayla Dizlere Vurma: Öğrenciler harekete başlamadan önce, iki el dizlerin üstünde sabit bir şekilde durmaktadır. Metronomdan gelen ritim sesiyle birlikte iki elini de sirayla kullanarak hareketi tamamlar. El seçiminde istediği el ile harekete başlar. Toplamda öğrenciler bir hareket boyunca 6 ritim vuruşu yapmaktadır.

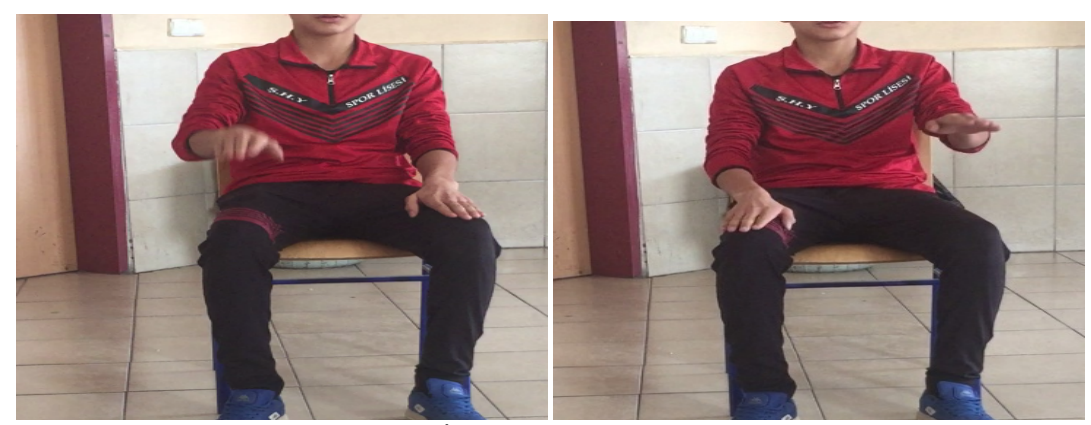

Şekil 2. İki el strayla dizlere vurma

Oturarak Yerinde Sayma: Öğrenciler, harekete başlamadan önce sandalyede oturur şekilde olmalıdır. Ayakları bir omuz genişliğin de açıktır. Vücut dik karşıya bakarlar. Metronom başladığında, metronomdan gelen ritim sesiyle birlikte iki ayağını da sırayla kullanarak hareketi tamamlar. Harekete istediği ayakla başlar. Toplamda öğrenciler bir hareket boyunca 6 ritim vuruşu yapmaktadır.

Ayakta Yerinde Sayma: Öğrenciler harekete başlamadan önce, vücut pozisyonu ayakta dik bir şekilde, ayaklar omuz genişliğinde açıktır. Metronom başladığında, metronomdan gelen ritim sesiyle birlikte iki ayağını da sırayla yukarı doğru diz kapağına kadar çekerek sırayla hareketi tamamlar. Harekete istediği ayakla başlar. Toplamda öğrenciler bir hareket boyunca 6 ritim vuruşu yapmaktadır. 
İleri Yürüme: Öğrenciler harekete başlamadan önce, vücut pozisyonu ayakta dik bir şekilde ayaklar omuz genişliğinde açıtır. Metronom başladığında, metronomdan gelen ritim sesiyle birlikte, iki ayağından istediğiyle sırayla ileriye doğru ayağını diz kapağına kadar çekerek harekete geçmektedir. Toplamda öğrenciler bir hareket boyunca 6 ritim vuruşu yapmaktadır.

Geriye Yürüme: Öğrenciler harekete başlamadan önce, vücut pozisyonu ayakta dik bir şekilde ayaklar omuz genişliğinde açıktır. Metronom başladığında, metronomdan gelen ritim sesiyle birlikte iki ayağından istediğiyle sırayla geriye doğru, ayağını diz kapağına kadar çekerek hareketi tamamlar. Toplamda öğrenciler bir hareket boyunca 6 ritim vuruşu yapmaktadır.

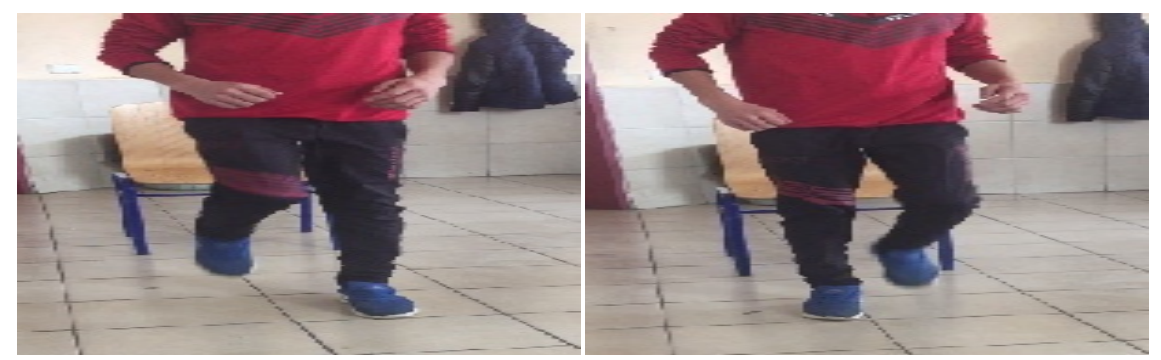

Şekil 3. Geriye yürüme

\section{Verilerin Değerlendirilmesi}

Video görüntülerinin değerlendirilmesinde alan uzmanlarına başvurulmuştur. Halk Oyunları alanında tecrübeli ve bu alanda ikinci kademe antrenörlük belgesine sahip iki hakem ile değerlendirmeler yapılmıştır. Hakemlerin birbirlerinden etkilememeleri için farklı günlerde videolar izletilerek değerlendirme formları* doldurtulmuştur. Birinci hakem halk oyunları alanında 11 yıl boyunca çeşitli kulüplerde eğitim görmüştür ve halk oyunları antrenörü olarak 6 yıldır görev yapmaktadır. İkinci hakem halk oyunları alanında 14 yıl boyunca çeşitli kulüplerde eğitim görmüştür ve halk oyunları antrenörü olarak 7 yıldır görev yapmaktadır. 
Uygulamaya katılacak katılımcıların bilgilerini almak için demografik bilgi formu dağıtılmıştır. Daha sonra çalışmanın ikinci kısmı olan metronom eşliğinde video çekimlerine geçilmiştir. Hakemlerle görüşme Ankara Dışkapı'da bulunan Yunus Emre Kültür Merkezi'nde görüşme sağlanmış olup, çalışma hakkında ön bilgilerin verildiği bir toplantı yapılmıştır. Toplantıda hakemlere bir kaç video izlettikten sonra değerlendirme için görüşleri alınmıştır. Hakemler puanlama yaparken, dikkat edilmesi gereken hususlar vurgulanmıştır. Birinci hakem saat 13.00 'da değerlendirmeye başlamış olup, saat 21.00' da değerlendirmeyi bitirmiştir (22.01.2019). Bir sonraki gün, ikinci hakem ile saat 12.30'da Yunus Emre Kültür Merkezinde buluşma sağlanmış olup, saat 13.00'da değerlendirmeye başlanmıştır. Değerlendirmenin bitişi 20.45'de gerçekleşmiştir (23.01.2019). Hakemlerin metronomun çıkardığı sesten bunalmaları ve diğer çeşitli ihtiyaçlar dolayısıyla ara ara molalar verilmiştir. Dikkat dağınıklığını önlemek açısından, hakem değerlendirmeleri sessiz, yeterli ışık ve 1 sı bulunan bir ortamda yapılmıştır.

Tablo 1. Ritim Becerisi Gözlem Formu

\begin{tabular}{|l|c|c|c|c|c|c|c|}
\hline \multirow{2}{*}{ Katılımcinın İsim ve Soyadı } & \multicolumn{7}{|c|}{ Tempo: 120} \\
\hline & 1 & 2 & 3 & 4 & 5 & 6 & Ort \\
\hline İki el dizlere vurma & & & & & & & \\
\hline İki el sirayla dizlere vurma & & & & & & & \\
\hline Oturarak yerinde sayma & & & & & & & \\
\hline Ayakta yerinde sayma & & & & & & & \\
\hline İleri yürüme & & & & & & & \\
\hline Geri yürüme & & \multicolumn{7}{|c|}{ Toplam Ortalama } & \\
\hline \multicolumn{7}{|c|}{} \\
\hline
\end{tabular}

\section{Akademik Başarının Tespiti}

Öğrencilerin akademik başarı düzeylerinin belirlenmesi için okul idarelerinden alınan Türk Dili ve Edebiyatı ders notları, Matematik ders notları ve tüm derslerin genel akademik not ortalamaları kullanılmıştır. 


\section{Verilerin analizi}

Elde edilen verilerin normal dağılıma uygun olup olmadığını ortaya koymak amacıyla Shapiro -Wilk normallik testi uygulanmıştır. Normallik sinaması sonucu olarak parametrik olmayan testlerden Kruskal Wallis- $\mathrm{H}$ testine başvurulmasına karar verilmiştir. Tüm verilerin analizinde SPSS 18 paket programı kullanılmıştır.

\section{Bulgular}

Tablo 1. "Türk Dili Edebiyatı dersi notu sınflamasına göre öğrencilerin ritmik yetenek puanlar arasında anlamlı bir fark olup olmadığına yönelik Kruskal Wallis testi sonuçları"

\begin{tabular}{|c|c|c|c|c|c|c|c|}
\hline Hakemler & $\begin{array}{c}\text { Toplam } \\
\text { Ritmik } \\
\text { Yetenek } \\
\text { puanı }\end{array}$ & $\begin{array}{c}\text { Türkçe } \\
\text { Ders } \\
\text { Notu }\end{array}$ & $\mathbf{N}$ & Ortalama & $\begin{array}{c}\text { Standart } \\
\text { Sapma }\end{array}$ & $\begin{array}{c}\text { Ki-kare } \\
\text { istatis- } \\
\text { tiği }\end{array}$ & $\mathbf{P}$ \\
\hline \multirow{6}{*}{ 1.Hakem } & \multirow{3}{*}{$\begin{array}{c}\text { Tempo } \\
120\end{array}$} & Düşük & 54 & 12.95 & 1.90 & \multirow{3}{*}{.336} & \multirow{3}{*}{.845} \\
\hline & & Orta & 7 & 12.90 & 1.12 & & \\
\hline & & Yüksek & 29 & 12.94 & 1.28 & & \\
\hline & \multirow{3}{*}{$\begin{array}{c}\text { Tempo } \\
132\end{array}$} & Düşük & 54 & 13.24 & 1.94 & \multirow{3}{*}{1.648} & \multirow{3}{*}{.439} \\
\hline & & Orta & 7 & 12.64 & 1.27 & & \\
\hline & & Yüksek & 29 & 12.61 & 1.61 & & \\
\hline \multirow{6}{*}{ 2.Hakem } & \multirow{3}{*}{$\begin{array}{c}\text { Tempo } \\
120\end{array}$} & Düşük & 54 & 13.68 & 2.45 & \multirow{3}{*}{2.460} & \multirow{3}{*}{.292} \\
\hline & & Orta & 7 & 13.20 & 2.64 & & \\
\hline & & Yüksek & 29 & 13.10 & 2.24 & & \\
\hline & \multirow{3}{*}{$\begin{array}{c}\text { Tempo } \\
132\end{array}$} & Düşük & 54 & 14.11 & 2.30 & \multirow{3}{*}{4.141} & \multirow{3}{*}{.126} \\
\hline & & Orta & 7 & 13.07 & 3.11 & & \\
\hline & & Yüksek & 29 & 13.21 & 2.43 & & \\
\hline
\end{tabular}

Katılımcıların Türk Dili ve Edebiyatı derslerinin not ortalamalarıyla hakemlerin 120 ve 132 tempolarda vermiş olduğu ritmik yetenek puanları arasında istatistiki olarak anlamlı bir sonuç tespit edilememiştir ( $>>0.05)$.

Katılımcıların Matematik derslerinin not ortalamalarıyla hakemlerin 120 ve 132 tempolarda vermiş olduğu ritmik yetenek puanları arasında istatistiki olarak anlamlı bir sonuç tespit edilememiştir ( $p>0.05)$. 
Tablo 2. Matematik dersi notu sınıflamasına göre öğrencilerin ritmik yetenek puanları arasında anlamlı bir fark olup olmadı̆̆ına yönelik Kruskal Wallis testi sonuçları

\begin{tabular}{|c|c|c|c|c|c|c|c|}
\hline Hakemler & $\begin{array}{c}\text { Toplam } \\
\text { Ritmik } \\
\text { Yetenek } \\
\text { puanı }\end{array}$ & $\begin{array}{l}\text { Ma- } \\
\text { tematik } \\
\text { Ders Notu }\end{array}$ & $\mathbf{N}$ & Ortalama & $\begin{array}{c}\text { Standart } \\
\text { Sapma }\end{array}$ & $\begin{array}{c}\text { Ki-kare } \\
\text { istatis- } \\
\text { tiği }\end{array}$ & $\mathbf{P}$ \\
\hline \multirow{6}{*}{ 1.Hakem } & \multirow{3}{*}{$\begin{array}{c}\text { Tempo } \\
120\end{array}$} & Düşük & 63 & 12.96 & 1.59 & \multirow{3}{*}{2.074} & \multirow{3}{*}{.354} \\
\hline & & Orta & 5 & 11.84 & 1.57 & & \\
\hline & & Yüksek & 22 & 13.15 & 1.84 & & \\
\hline & \multirow{3}{*}{$\begin{array}{c}\text { Tempo } \\
132\end{array}$} & Düşük & 63 & 12.92 & 1.85 & \multirow{3}{*}{.937} & \multirow{3}{*}{.626} \\
\hline & & Orta & 5 & 12.62 & 1.28 & & \\
\hline & & Yüksek & 22 & 13.27 & 1,81 & & \\
\hline \multirow{6}{*}{ 2.Hakem } & \multirow{3}{*}{$\begin{array}{c}\text { Tempo } \\
120\end{array}$} & Düşük & 63 & 13.58 & 2.48 & \multirow{3}{*}{2.645} & \multirow{3}{*}{.267} \\
\hline & & Orta & 5 & 11.56 & 1.41 & & \\
\hline & & Yüksek & 22 & 13.51 & 2.16 & & \\
\hline & \multirow{3}{*}{$\begin{array}{c}\text { Tempo } \\
132\end{array}$} & Düşük & 63 & 13.91 & 2.45 & \multirow{3}{*}{3.546} & \multirow{3}{*}{.170} \\
\hline & & Orta & 5 & 11.54 & 2.31 & & \\
\hline & & Yüksek & 22 & 13.75 & 2.20 & & \\
\hline
\end{tabular}

Katılımciların bütün derslerinin genel not ortalamalarıla hakemlerin 120 ve 132 tempolarda vermiş olduğu ritmik yetenek puanları arasında istatistiki olarak anlamlı bir sonuç tespit edilememiştir ( $p>0.05)$.

Tablo 3. Tüm derslerin genel akademik not ortalaması sınıflamasına göre öğrencilerin ritmik yetenek puanları arasında anlamlı bir fark olup olmadığına yönelik Kruskal Wallis testi sonuçlan

\begin{tabular}{|c|c|c|c|c|c|c|c|}
\hline Hakemler & $\begin{array}{c}\text { Toplam } \\
\text { Ritmik } \\
\text { Yetenek } \\
\text { puanı }\end{array}$ & $\begin{array}{l}\text { Genel Not } \\
\text { Ortalaması }\end{array}$ & $\mathbf{N}$ & Ortalama & $\begin{array}{c}\text { Standart } \\
\text { Sapma }\end{array}$ & $\begin{array}{c}\text { Ki-kare } \\
\text { istatistiği }\end{array}$ & $\mathbf{P}$ \\
\hline \multirow{6}{*}{ 1.Hakem } & \multirow{3}{*}{$\begin{array}{c}\text { Tempo } \\
120\end{array}$} & Düşük & 37 & 12.59 & 1.54 & \multirow{3}{*}{3.452} & \multirow{3}{*}{.178} \\
\hline & & Orta & 19 & 13.40 & 1.70 & & \\
\hline & & Yüksek & 34 & 13.07 & 1.73 & & \\
\hline & \multirow{3}{*}{$\begin{array}{c}\text { Tempo } \\
132\end{array}$} & Düşük & 37 & 12.82 & 1.74 & \multirow{3}{*}{.490} & \multirow{3}{*}{.783} \\
\hline & & Orta & 19 & 13.12 & 2.08 & & \\
\hline & & Yüksek & 34 & 13.09 & 1.76 & & \\
\hline \multirow{6}{*}{ 2.Hakem } & \multirow{3}{*}{$\begin{array}{c}\text { Tempo } \\
120\end{array}$} & Düşük & 37 & 13.05 & 2.33 & \multirow{3}{*}{3.559} & \multirow{3}{*}{.169} \\
\hline & & Orta & 19 & 14.52 & 2.65 & & \\
\hline & & Yüksek & 34 & 13.30 & 2.18 & & \\
\hline & \multirow{3}{*}{$\begin{array}{c}\text { Tempo } \\
132\end{array}$} & Düşük & 37 & 13.52 & 2.11 & \multirow{3}{*}{2.052} & \multirow{3}{*}{.358} \\
\hline & & Orta & 19 & 14.58 & 3.04 & & \\
\hline & & Yüksek & 34 & 13.51 & 2.32 & & \\
\hline
\end{tabular}




\section{Sonuç ve Değerlendirme}

Sonuç olarak katılımcıların ritmik yetenek puanları ile akademik başarı not ortalamaları arasında istatiksel olarak anlamlı bir ilişki tespit edilememiştir.Araştırma kapsamında bulunan 90 öğrencinin \%76'llk kısmı yani 68 kişi herhangi bir spor faaliyetine lisans seviyesinde katılmadığını belirtirken, \%24'lük kısmı yani 22 kişi futbol, oryantring, halter, güreş vb. 11 birbirinden farklı branşta lisanslı şekilde yaptıklarını ifade etmişlerdir. Katılımcıların sporcu lisansına sahip olup olmamaları çalışmanın sonucunu istatistiki anlamda etkilememiştir. İki hakemin 120 ve 132 tempolarda verdikleri puanlarının ortalamaları arasında istatistik olarak anlamlı bir ilişki tespit edilmemiştir.

Öğrencilerin ne Türk Dili ve Edebiyatı ne de Matematik derslerindeki akademik başarılarıyla ritmik yetenekleri arasında anlamlı bir ilişki gözlenmemiştir. Aynı katılımcıların genel not ortalamaları söz konusu olduğunda da sonucun değişmediği görülmüştür. İlköğretim öğrencilerine yönelik olarak gerçekleştirilmiş olan bir başka araştırmadaysa özellikle 1., 3. ve 4. sinıflarda okuma anlama düzeyleri ile ritmik yetenek arasında oldukça anlamlı bir ilişki belirlenmiştir (Horne, 2002). Benzer bir çalışmada performans sanatları ile akademik başarı arasındaki ilişkinin araştırıldığı bir çalışma da İngilizce ve Matematik derslerindeki başarı ile performans sanatlarına katılım arasında oldukça dikkate değer bir ilişki saptanmıştır (Thomas, 2011). Bir başka araştırmadaysa, lisedeki öğrencilerin akademik başarıları ile bando (müzik topluluğu) topluluklarına katılımları arasındaki ilişkinin araştırılması için 50 öğrenciyle sürdürülmüş olan çalışmanın sonucunda da akademi başarıyla bandoya katılım arasında olumlu bir ilişki saptanmıştır (Edstrand, 2015).

Yukarıda bahsi geçen bazı araştırmalarda akademik başarı ile ritmik yetenek arasında anlamlı ve pozitif sonuçlar ortaya çıkmıştır. Bu çalışmada sonucun bu şekilde olmasının örneklem grubunun genel özellikleriyle ilişkili olduğu düşünülmektedir. Ayrıca ölçme aracı (Rhytmic Compentence Analysis Test- RCAT), katılımcı sayıları gibi pek çok faktörün de araştırma sonuçlarına etkide bulunmuş olacağı varsayımlar arasındadir. 


\section{EXTENDED ABSTRACT}

\section{The Relationship Between Rhythmic Ability and Academic Success \\ * \\ Hüseyin Yıldız - Oğuzhan Yoncalık \\ Kırıkkale University}

In the span of the subject "Musical Intellect", "Being aware of the forms of music and their classification and expression" is how it is defined as a phrase (Eyyam, Menevish and Doğruer, 2010). Performance rhythm is as its creation is in bondage with time and space, is said as being successful in the area of motor skills (Pollataou, Konstantina and Vasilios, 2005). That is why out of every action that is done with desire and with immense frequency that has a scale and a value is measured by its association with "speed and rhythm" (Langhans and Lau, 1972). Also, every action has its own rhythm and actions without rhythm are like sentences that are trying to be meaningful without stops and commas (Tortora, 2010). The correlation and difference of time and space between actions are defined by their ability of rhythm. Also the ability of rhythm as an already member of the motor memory is an occasion for a new rhythm to occur (Minz, 2003). In a lot of sports competitions, there's rhythm. For example; while playing basketball, actions like "going to the basket, dribbling, tourniquet" all has their dynamisms to them, as well as their own rhythms (Sayin, 2011). And even in the orientring sport, performing the moves rhythmically is a direct component to the final result (Langhans and Lau, 1972). In this sport, the players that are in an open field are required to perform actions like "bouncing, side sweeping or jumping) immediately. In another study about footballers, their moves, position changes and plays around the ball", to be done succesfully, require a certain amount of rhythm ability (Moreno, 2001).

\section{Aim of Research}

In this study the point is to evaluate and research the correlation between rhythmic abilities and academic success. 


\section{Method}

Research has been conducted in year of 2018-2019 on four high schools in Kırıkkale 90 (48 female - 42 male) 9th class students that are in continuation of their education. The age of participants were identified as 14-15. No out of the ordinary physical or mental conditions were seen on the participants. The rhythmic abilities of the students were identified with Wekiart (1989) rhythm competence analysis test (RCAT). The tests on the students are all monitored and recorded. The starting points of the students and camera positions were designated as 3.15 meters. The metronome and speakers were located for the students' comfort to hear the metronome properly, and in their right-hand side desks.

The moves were done with 120 and 132 beats per minute in metronome and with two distinct tempos. Before the start, students were informed about the study. The median level of the moves were shown to the students. Every student was participating independently. No visual or vocal help was given to the students. Participating students repeated every move 6 times and with the two rhythms combined, performed them 72 times. The moves made with 120 and $132 \mathrm{bpm}$ (beats per minute) were the same.

The evaluation of the video tapes were made by field specialists. Two referees that are experienced with folk dances that has second degree trainer licenses were commissioned. For the sake of not being affected by one another's perspectives, the two referees were made to watch the said videos in separate days. Demographics were given to the participants to gather their information. And after that, the second phase of the study was conducted; video shoots with metronome. The intermission with the referees were made in Yunus Emre Kültür Merkezi at Dışkapi/Ankara and an informational meeting was made about the study. In the meeting, after showing the referees the videos, their views were taken for evaluation. The points of observation were given to the referees before starting. First referee started at (22.01.2019) and the other referee has started the day after (23.01.2019). Because of the distress from the constant sound of metronome and other various humanly needs, small breaks were given.

To determine the said student's academic performance, their marks on Turkish Language and Literature, Maths and GPA were used. 
Shapiro-Wilk normality test was conducted for the sake of determining the normal distribution of the information that has been gathered by the study and research. As a result of the normality test, non-parametric test of Kruskal Wallis-H was also conducted. SPSS18 packet program was used in analysis of all data.

\section{Conclusion}

As a result, no correlation between the students' academic success and their rhythmic ability was found. 68 students out of 90 were found to be not participating in sports at licence-level at all. 22 out of 90 was found to be participating in various sports such as football, lifting, wrestling and orienting. The licenses of participants were found to be not affecting the result statistically. Statistically, the points that were given neither to 120 nor 132 bpm's means were ineffective.

Association with rhythmic abilities or points on neither Turkish Language and Literature nor Mathematics with their students were relevant to the points they got from the test. Same participants GPA also gave the same notice that they were irrelevant. Another study that targeted primary school showed that their rhythmic abilities correlated with their ability to read, especially in grades 1, 2 and 4 (Horne, 2002). A similar study, researching the relevance between performance arts and academic success, success in English and Mathematics lessons is in a direct relationship with their rhythmic abilities (Thomas, 2011). In another research that studied the participation of high school students in school band and about their academic and their correlation with their academic success also gave a positive impression about their relation with rhythmic abilities (Edstrand, 2015).

The researches that are said above are giving a positive influence about the interrelation of academic success and rhythmic abilities. In this study, it is thought that the targeted individuals' properties have changed the result to be different than usual. And also factors like the measurement tool (Rhythmic Competence Analysis Test-RCAT), number of the participants also considered to be among the assumptions that are affecting the result. 


\section{Kaynakça / References}

Arıc1, İ. (2007). Ilköğretim din kültürü ve ahlak bilgisi dersinde öğrenci başarısını etkileyen faktörler ankara örneği.( Yayınlanmamış doktora tezi). Ankara Üniversitesi, Ankara.

Dane, A., Kudu, M. ve Balkı, N. (2009). Lise öğrencilerinin algılarına göre, matematik başarısını olumsuz yönde etkileyen faktörler. EÜFBED Fen Bilimleri Enstitüsü Dergisi, 2(1), 17-34.

Dogan, F. ve Altay, F. (1990). Sportif ve ritmik jimnastik. Ankara: Ünal Ofset Yayınevi.

Erdoğdu, Y. (2006). Yaratıcılık ile öğretmen davranışları ve akademik başarı arasındaki ilişkiler. Elektronik Sosyal Bilimler Dergisi, 5(17), 95-106.

Edstrand, C. S. (2015). A comparative analysis of students' involved and not involved in high school band and academic achievement (Doctoral Dissertation). ProQuest Dissertations and Theses veri tabanından 19.09.2019 tarihinde erişilmiştir. (UMI No. 3702597)

Eyyam, R., Meneviş, İ. ve Doğruer, R. N. (Kasım,2010). Çoklu zeka ve akademik başarı arasindaki ilişki, Paper Presented at International Conference on New Trends in Education and Their Implications, Antalya: 916-919.

Gerek, Z. ve Kitkat, D. (2006). Elit Sporcuların ve sedanterlerin ritim duyguları bakımından karşılaştırılması. Atatürk Üniversitesi Beden Ĕ̆itimi Spor Bilimleri Dergisi, 8(1), 36-42.

Horne, A. J. (2002). Examining relationships among rhythm aptitude rhythm achievement and reading achievement (Doctoral Dissertation). ProQuest Dissertations and Theses veri tabanından 19.09.2019 tarihinde erişilmiştir.

Kaynak, T. (2009). Müziksel performansın ölçülmesinde dereceli ölçme aracına ilişkin öğretim elemanı görüşleri. Fine Arts, 13(3), 23-30.

Langhans, H. ve Lau, H. (1972). Das schlagwerk handtrom melübungund anleitung zur bewegungs begleitung fürtanz rhythmik, gymnastik, sportund buch straus. Zürich: Pelikan Edition

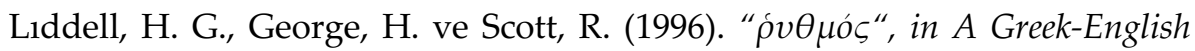
Lexicon, Revised edition, combining the text of the ninth edition with an extensively revised and expanded supplement. Oxford and New York: Oxford University Press.

Moreno, J. H. (2001). Anàlisi dels paràmetres espai i temps en el futbol sala. La distància recorreguda, el ritme i la direcció del desplaçament del 
jugador durant un partit de competició. Apunts. Educació física i esports, 3(65), 32-44.

Minz, A. K. (2003). Relationship of coordinative abilities to performance in badminton. (Master Thesis) Accesing from Lakshmibai National Institute of Physical Education Deemed University database.

Peker, M. ve Mirasyedioğlu, İ. (2003). Lise 2. sinıf öğrencilerinin matematik dersine yönelik tutumları ve başarıları arasındaki ilişki. Pamukkale Üniversitesi Ĕ̆itim Fakültesi Dergisi, 2(14), 157-166.

Pollatou, E., Konstantina, K. ve Vasilios, G. (2005). Gender differences in musical aptitude, rhythmic ability and motor performance in preschool children. Early Child Development and Care, 175(4), 361-369.

Sarı, M. H., Arıkan, S., ve Yıldızlı, H. (2017). 8. sınıf matematik akademik başarısını yordayan faktörler-TIMSS 2015. Eğitimde ve Psikolojide Ölçme ve Değerlendirme Dergisi , 8 (3), 246-265.

Sarı, M. H., ve Ekici, G. (2018). İlkokul 4. sınıf öğrencilerinin matematik başarıları ile aritmetik performanslarını etkileyen duyuşsal değişkenlerin belirlenmesi. OPUS-Uluslararası Toplum Araştırmaları Dergisi, 8(15), 1562-1594. DOI: 10.26466/opus.451025.

Sögüt, M. (2009). The effects of rhythm training on tennis performance. (Doctoral Dissertation). Middle East Technical University, The Deparment of Physical Education and Sports, Accessed from YÖK database.

Thomas, T. D. (2011). The impact of musical performing arts on the academic achievement of black males (Doctoral Thesis). Accessed from Quest Dissertations \& Theses database.

Tortora, S. (2006). The Dancing dialogue: Using the communicative power of movement with young children. Baltimore: Brookes.

Uçan, A. (1997). Müzik eğitimi. Ankara: Müzik Ansiklopedisi Yayınları.

Weikart, P. S. (1989). Teaching movement and dance. A sequential to rhythmic movement (Third Edition). United States of America: The High/Scope Press.

\section{Kaynakça Bilgisi / Citation Information}

Yıldız, H. ve Yoncalık, O. (2019). Ritmik yetenek ile akademik başarı arasındaki ilişki. OPUS-Uluslararası Toplum Araştırmaları Dergisi, 14(20), 1431-1447. DOI: 10.26466/opus.626271 